\title{
Comparison of Bite Force with Locking Plates versus Non-Locking Plates in the Treatment of Mandibular Fractures: A Meta-Analysis
}

\author{
José Cristiano Ramos Glória ${ }^{1}$ Ighor Andrade Fernandes ${ }^{1}$ Esmeralda Maria da Silveira ${ }^{2}$ \\ Glaciele Maria de Souza ${ }^{1}$ Ricardo Lopes Rocha ${ }^{2}$ Endi Lanza Galvão ${ }^{3}$ Saulo Gabriel Moreira Falci ${ }^{1}$ \\ ${ }^{1}$ Department of Oral and Maxillofacial Surgery, Universidade Federal \\ dos Vales do Jequitinhonha e Mucuri, Diamantina, MG, Brazil \\ 2 Department of Dentistry, Universidade Federal dos Vales do \\ Jequitinhonha e Mucuri, Diamantina, MG, Brazil

\begin{abstract}
Address for correspondence Ighor Andrade Fernandes, DDs, Departmento de Cirurgia Oral e Maxilofacial, Universidade Federal dos Vales do Jequitinhonha e Mucuri, Rua da Glória 187, Diamantina, Minas Gerais, 39100-000, Brazil (e-mail: ighor.af@gmail.com).
\end{abstract}

${ }^{3}$ Research Department, Centro de Pesquisas Rene Rachou, Belo Horizonte, MG, Brazil

Int Arch Otorhinolaryngol 2018;22:181-189.

\begin{abstract}
Keywords

- bite force

- mandibular fracture

- fracture fixation

- bone plates

- internal fixators

Introduction Mandibular fractures represent a high percentage of all facial fractures, and the bite force is a fundamental parameter to measure the actual mandibular function and, subsequently, the masticatory efficiency and quality of life.

Objectives The purpose of the present systematic review was to verify if there is any difference in the bite forces of patients with mandibular fractures fixed by locking or non-locking plates, testing the null hypothesis of no difference in this parameter.

Data Synthesis A systematic review of the literature was conducted using four databases (PubMed, Virtual Health Library, Web of Science and Science Direct) without restrictions as to publication date or language. We found 3,039 abstracts, and selected 4 articles for this review.

Conclusion The overall results show better performance in bite force for the locking plates when compared with the non-locking plates in the incisor region (mean deviation [MD]: 1.18; 95\% confidence interval [95\%Cl]: 0.13-2.23), right molar region (MD: 4.71; 95\%Cl: 0.63-8.79) and left molar region (MD: 10.34; 95\%Cl: 4.55-16.13). Although the results of this study indicated a better bite force result with the locking plates, there is still no sufficient evidence to support this information safely.
\end{abstract}

\section{Introduction}

Mandibular fractures represent a high percentage of all facial fractures. $^{1-3}$ The most common causes of these injuries are interpersonal violence, falls, lesions practicing sports, and accidents at work and traffic accidents. ${ }^{4}$ The consequences of mandibular fractures can include malocclusion, temporomandibular joint syndrome, and poor mastication, ${ }^{5}$ leading to a decrease in quality of life. ${ }^{6}$

received

April 1, 2017

accepted

May 9, 2017

published online

July 14, 2017 10.1055/s-0037-1604056. ISSN 1809-9777.
The mandibular fracture fixation by metallic plates was first described by Michelet in $1973,{ }^{7}$ and was subsequently improved by Champy in $1975,{ }^{8}$ who described the ideal places in the mandible to apply plates that could resist to torsional forces during osteosynthesis. The standard plate system works when the heads of the screws compress the plate to the bone to maintain stability, preventing changes in the alignment of the fragments and maintaining occlusal stability. ${ }^{9}$ On the other hand, the locking plate system

Copyright $\odot 2018$ by Thieme Revinter Publicações Ltda, Rio de Janeiro, Brazil

\section{License terms}

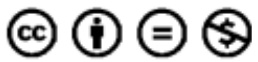


attaches the plates to the bone by locking the screws to both the bone and the plate, which maintains the stability of the system. ${ }^{10}$ Therefore, treatments with locking plates lead to fewer changes in occlusal relationships, fewer screw-loosening events, less problems with bone vascularization, greater stability between fragments, and easier placement of the plates when compared with treatments with non-locking systems. $^{11,12}$

Some characteristics of the locking plate systems are recognized as disadvantages, such as the fact that they are more expensive than the standard systems, and need a specific apparatus in order to be applied in the bone. Thus, for each method and instrument launched by new studies, it is necessary to evaluate the actual advantages and disadvantages, so they may be properly applied in clinical situations. According to a recent meta-analysis, ${ }^{13}$ there are no significant differences in the postoperative complication rates with the use of locking plate systems when compared with the use of standard plate systems in the management of mandibular fractures, but this study did not assess the bite force measurements. Bite force is a fundamental parameter to measure the actual mandibular function and, subsequently, the masticatory efficiency and quality of life.

The purpose of the present systematic review was to verify if there is any difference in the bite force of patients with mandibular fractures fixed by locking or non-locking plates, testing the null hypothesis of no difference in this parameter.

\section{Review of the Literature}

The present study was conducted according to the Cochrane Handbook for Systematic Reviews of Interventions (apud Chrcanovic, 2014), ${ }^{13}$ and the Preferred Reporting Items for Systematic Reviews and Meta-Analyses (PRISMA) statement using the Review manager (RevMan) software, version 5.3 (The Cochrane Collaboration, Copenhagen). It was registered in the International Prospective Register of Systematic Reviews (PROSPERO; CRD42016051937).

We conducted an electronic search to identify relevant literature published since November 11, 2016, in the PubMed, the Virtual Health Library (VHL), the Web of Science and the Science Direct databases. The search was performed using four different combinations of terms in all databases, following these stages: stage 1-(mandibular fracture) AND osteosynthesis AND (bite force); stage 2-(mandibular fracture) AND osteosynthesis AND (occlusal force); stage 3(mandibular fracture) AND osteosynthesis AND (masticatory force); and stage 4-(mandibular fracture) AND (locking plate OR non-locking plate OR non-locking plate OR standard plate OR conventional plate).

Furthermore, we also searched the gray literature (Google Scholar), published theses (http://bancodeteses.capes.gov. br/banco-teses), and the reference lists of all studies identified as relevant reviews for possible additional studies. We also searched for relevant ongoing clinical trials in the Clinical Trials Registry (http://www.clinicaltrials.gov).

The included studies must have reported the criteria for bite force measurement of the patients and the follow-up measurements. The exclusion criteria were: textbooks, case reports, technical reports, review papers, opinion articles, cover letters, in vitro studies, animal studies, and papers without available abstracts. After independently reading paper titles and abstracts, the reviewers checked the results of the selected papers. Disagreements were resolved by consensus. The same process was performed when reading the full text for the final inclusion of the papers in the systematic review.

After the database search, 3,039 studies were identified. After removing duplicates, 1,697 studies remained. After screening titles and abstracts, we retrieved 25 full-text studies. The reference lists of the selected papers and a hand search revealed one additional relevant paper. A total of 4 studies involving 130 patients ${ }^{4,14-16}$ evaluated bite force and were included in the qualitative synthesis (-Fig. 1). One study was mentioned in two separate papers ${ }^{14,16}$ that reported the same statistical data. These two articles were thus considered a single paper for the meta-analysis. One study presented the results through graphs, and it was not possible to extract the adequate statistical data for it. ${ }^{15}$ The author was contacted by e-mail, but we could not obtain an answer. Therefore, only two studies $^{4,14}$ were included in the meta-analyses.

The relevant characteristics of the included studies are presented in - Table 1. All studies evaluated and compared the bite force of patients treated with locking and nonlocking plates for the osteosynthesis of the mandibular fractures. The follow-up periods ranged from 1 to 12 weeks. The number of fractures ranged from 31 to 34 . Out of the four studies, three used the very own patients as controls by measuring the bite force preoperatively. All plates systems were $2.0 \mathrm{~mm}$ (-Table $\mathbf{1}$ ). The results were checked by reviewers after data collection to ensure accuracy.

The quality of the included studies was independently assessed by the same reviewers using a specific protocol developed by Higgins \& Green (2011, apud Chrcanovic, 2014) 13 for the assessment of the risk of bias. The classification of the potential risk of bias for each study was based on the following criteria: sequence generation; allocation sequence concealment; blinding of participants, personnel, and outcome assessors; incomplete outcome data; and selective outcome reporting. Each study was submitted to analysis, and the criteria were rated as exhibiting low, high, or unclear (no information or uncertain) risk of bias. The disagreements between reviewers were resolved by consensus for the final classification. Our assessment is presented in -Fig. 2.

The meta-analysis was performed using the R software ( $R$ Foundation for Statistical Computing, Vienna, Austria), version 3.3.1. The packages "meta" and "metafor" were used to perform the statistician calculation and the forest plots. The heterogeneity of the results of the studies was assessed using the I-squared $\left(\mathrm{I}^{2}\right)$ test. Values above $25 \%$ and $50 \%$ were considered indicatives of moderate and high heterogeneity respectively. As heterogeneity was present $\left(\mathrm{I}^{2}>0\right)$ in all tests, the random effect model was used to perform the meta-analysis. $^{17,18}$

The effect estimates were expressed as the weighted mean difference between the groups, and were obtained 


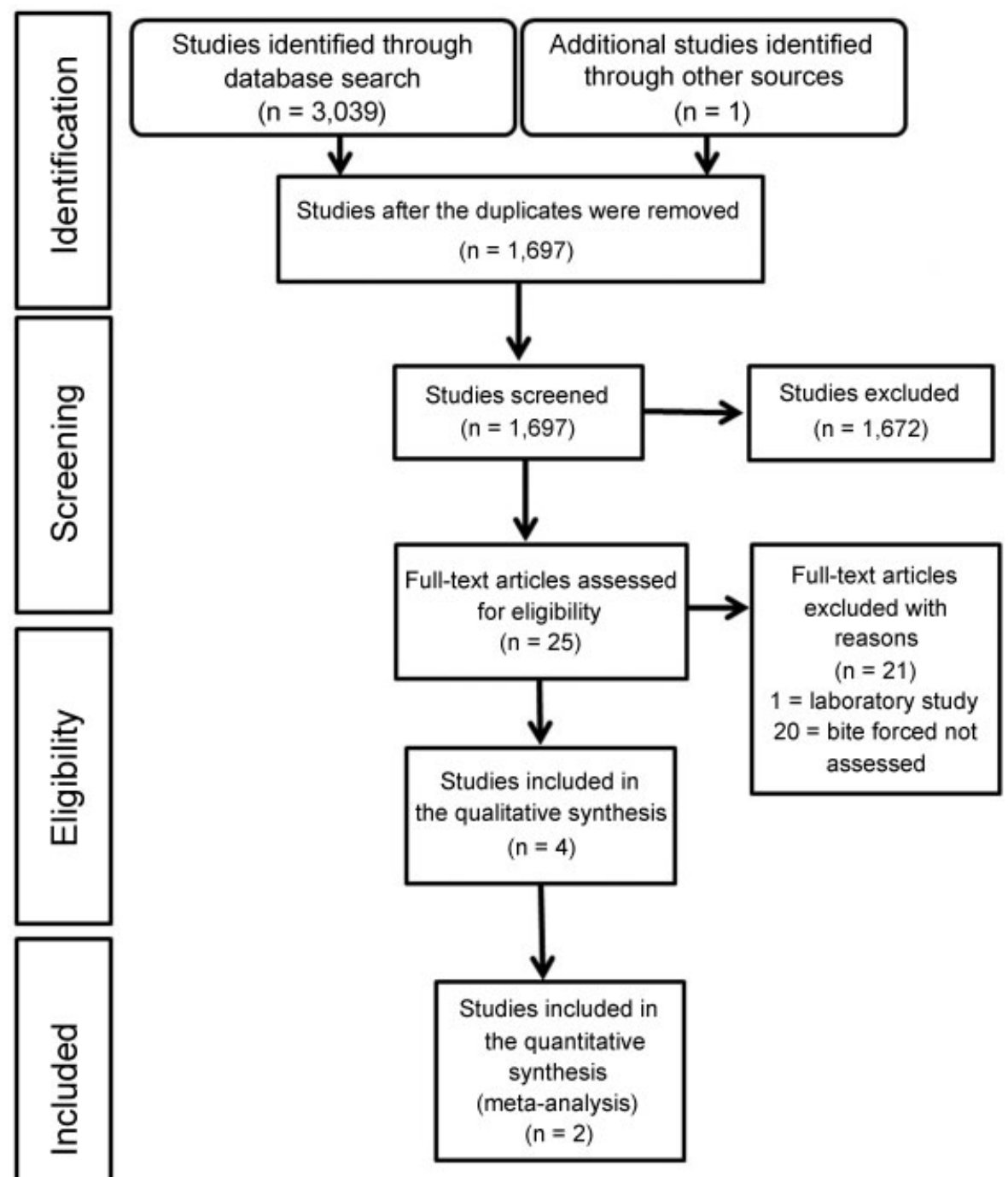

Fig. 1 Selection of studies for the systematic review.

by comparing the baseline mean values at the end of the study for each group.

All studies evaluated the bite forces by the same method, using the indigenous Bite Force Recorder, which consists of four strain gauges mounted on steel bars, forming a Wheatstone bridge. Load changes in the steel bar produced a measurable voltage change across the four strain gauges. All measurements were made with the patient seated with the head upright, in an unsupported natural head position, and looking forward. The patients were instructed to bite on the pads of bite force gauge to the maximal level. The results were analyzed in the follow-ups at $1,3,6$, and 12 weeks, observing the mean of the bite force measurements in the incisor, left molar, and right molar regions (- Table 2). ${ }^{4,14-16}$

The results of the meta-analysis showed that when the bite force in the incisor region was evaluated, the patients treated with locking plates showed no difference in bite force when compared with the patients treated with non-locking plates in the first (mean deviation [MD] :0.84; 95\% confi- dence interval [95\%CI]: $-0.62-2.30)$, third (MD: 0.91; 95\%CI: -0.29-2.10), and sixth (MD: 1.05; 95\%CI: -1.11-3.20) weeks. However, when evaluating the pooled bite force including 3 months of follow-up, the locking plates obtained better results than the non-locking plates for the osteosynthesis of mandibular fractures (MD: 1.18; 95\%CI: 0.13-2.23; $\left.\mathrm{I}^{2}=57.2 \%\right)$ (-Fig. 3).

The patients treated with locking plates showed no difference in bite force in the right molar region in the first (MD: 1.45; 95\%Cl: $-1.24-4.14$ ), third (MD: 1.18 ; 95\%Cl: -2.82-5.18) and sixth (MD: 7.47; 95\%CI: -6.85-21.78) weeks when compared with the patients treated with non-locking plates. However, the effect of the locking plates considering 3 months of follow-up was better than the effect of the non-locking plates (MD: 4.71; 95\%CI: 0.63-8.79; $\mathrm{I}^{2}=76.8 \%$ ) (-Fig. 4). Regarding the left molar region, locking plates and non-locking plates did not differ significantly in the first (MD: 5.46; 95\%CI: $-2.85-13.78$ ), third (MD: 8.16; 95\%CI: $-5.25 ; 21.58$ ), and sixth (MD: $12.47 ; 95 \% \mathrm{CI}:-9.85 ; 34.79$ ) 


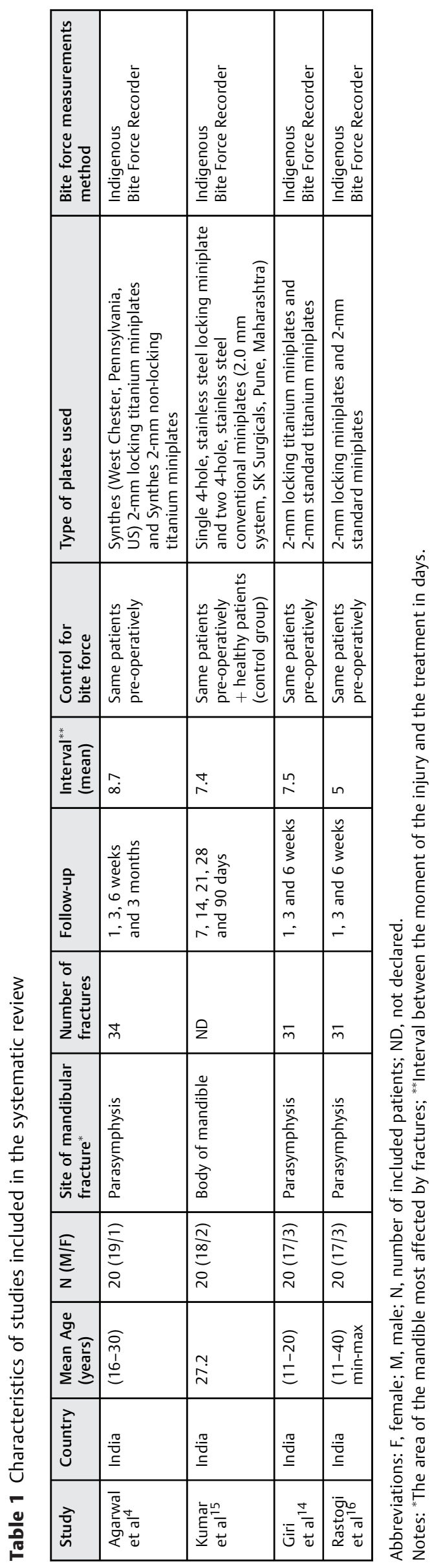

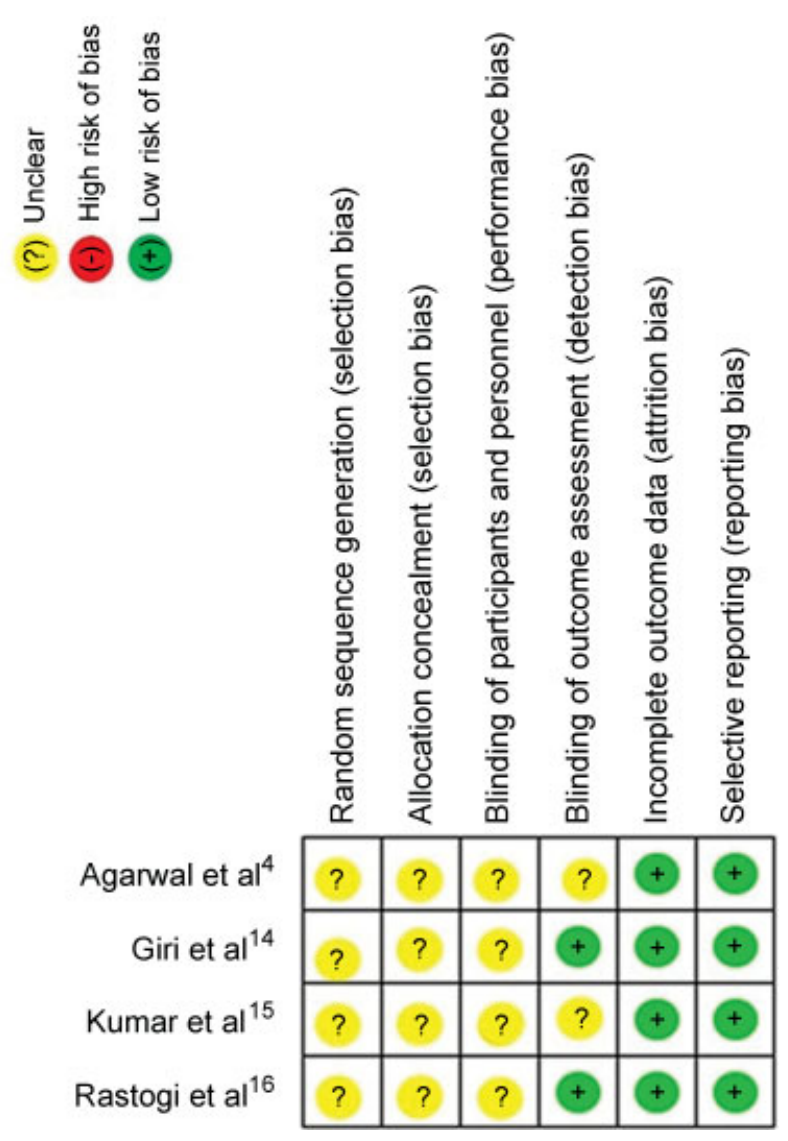

Fig. 2 Risk of bias assessment.

weeks of follow-up. The analysis after 3 months of follow-up showed that the locking plates obtained better results for bite force than the non-locking plates for the osteosynthesis of mandibular fractures (MD: 10.34; 95\%CI: 4.55-16.13; $\left.\mathrm{I}^{2}=89.2 \%\right)($ - Fig. 5).

\section{Discussion}

When comparing the use of locking and non-locking plate systems for the osteosynthesis of mandibular fractures, several clinical parameters have already been analyzed and published in two systematic reviews. ${ }^{13,19}$ However, none of these studies compared the bite forces of the patients after surgeries that used these plate systems. It has been proved that the bite force is a primordial factor for masticatory performance, ${ }^{20-22}$ having a significant influence on the patients' quality of life. ${ }^{23}$ As the current trend in the treatment of facial fractures through osteosynthesis is the early reestablishment of the function of the stomatognathic system, understanding the advantages and disadvantages of these two fixation plate systems in this variable is necessary. The results of the present review suggest that there was no difference in bite force evaluated between the two fracture fixation systems until the sixth week, although a gradual increase in bite force was verified until the third postoperative month in both groups. Nevertheless, better bite force was observed in the groups of locking plates after three months 
Table 2 Data extracted from the included studies (mean and standard deviation of bite forces)

\begin{tabular}{|c|c|c|c|c|c|c|}
\hline \multicolumn{7}{|c|}{ Follow-up $1^{\text {st }}$ week } \\
\hline \multirow[t]{2}{*}{ Author, year } & \multicolumn{2}{|c|}{ Incisor region: Mean \pm SD } & \multicolumn{2}{|c|}{ Left molar region: Mean \pm SD } & \multicolumn{2}{|c|}{ Right molar region: Mean $\pm S D$} \\
\hline & Locking & Non-locking & Locking & Non-locking & Locking & Non-locking \\
\hline Agarwal et $\mathrm{al}^{4}$ & $2.47 \pm 1.74$ & $0.90 \pm 0.91$ & $14.6 \pm 6.30$ & $4.73 \pm 3.74$ & $8.39 \pm 5.72$ & $5.55 \pm 3.68$ \\
\hline Giri et al ${ }^{14}$ & $5.54 \pm 1.67$ & $5.46 \pm 1.22$ & $16.92 \pm 2.87$ & $15.54 \pm 4.26$ & $16.60 \pm 3.45$ & $16.10 \pm 4.46$ \\
\hline Kumar et al ${ }^{15}$ & ND & ND & ND & ND & ND & ND \\
\hline Rastogi et al ${ }^{16}$ & $5.54 \pm 1.67$ & $5.46 \pm 1.22$ & $16.92 \pm 2.87$ & $15.54 \pm 4.26$ & $16.60 \pm 3.45$ & $16.10 \pm 4.46$ \\
\hline \multicolumn{7}{|c|}{ Follow-up $3^{\text {rd }}$ week } \\
\hline \multirow[t]{2}{*}{ Author, year } & \multicolumn{2}{|c|}{ Incisor region: Mean \pm SD } & \multicolumn{2}{|c|}{ Left molar region: Mean \pm SD } & \multicolumn{2}{|c|}{ Right molar region: Mean \pm SD } \\
\hline & Locking & Non-locking & Locking & Non-locking & Locking & Non-locking \\
\hline Agarwal et $\mathrm{al}^{4}$ & $4.22 \pm 2.45$ & $2.61 \pm 1.75$ & $27.79 \pm 11.85$ & $12.23 \pm 5.94$ & $20.52 \pm 9.58$ & $15.26 \pm 9.69$ \\
\hline Giri et al ${ }^{14}$ & $7.26 \pm 1.96$ & $6.85 \pm 1.59$ & $19.83 \pm 2.19$ & $18.00 \pm 4.97$ & $19.5 \pm 2.17$ & $19.34 \pm 4.99$ \\
\hline Kumar et al ${ }^{15}$ & ND & ND & ND & ND & ND & ND \\
\hline Rastogi et al ${ }^{16}$ & $7.26 \pm 1.96$ & $6.85 \pm 1.59$ & $19.83 \pm 2.19$ & $18.00 \pm 4.97$ & $19.5 \pm 2.17$ & $19.34 \pm 4.99$ \\
\hline \multicolumn{7}{|c|}{ Follow-up $6^{\text {th }}$ week } \\
\hline \multirow[t]{2}{*}{ Author, year } & \multicolumn{2}{|c|}{ Incisor region: Mean \pm SD } & \multicolumn{2}{|c|}{ Left molar region: Mean \pm SD } & \multicolumn{2}{|c|}{ Right molar region: Mean \pm SD } \\
\hline & Locking & Non-locking & Locking & Non-locking & Locking & Non-locking \\
\hline Agarwal et al ${ }^{4}$ & $7.93 \pm 4.94$ & $5.17 \pm 2.41$ & $43.27 \pm 13.80$ & $18.99 \pm 6.08$ & $37.92 \pm 10.44$ & $22.73 \pm 7.40$ \\
\hline Giri et al ${ }^{14}$ & $8.83 \pm 1.97$ & $8.49 \pm 1.39$ & $22.69 \pm 2.09$ & $21.20 \pm 5.70$ & $23.64 \pm 3.02$ & $23.08 \pm 5.99$ \\
\hline Kumar et al ${ }^{15}$ & ND & ND & ND & ND & ND & ND \\
\hline Rastogi et al ${ }^{16}$ & $8.83 \pm 1.97$ & $8.49 \pm 1.39$ & $22.69 \pm 2.09$ & $21.20 \pm 5.70$ & $23.64 \pm 3.02$ & $23.08 \pm 5.99$ \\
\hline \multicolumn{7}{|c|}{ Follow-up $3^{\text {rd }}$ month } \\
\hline \multirow[t]{2}{*}{ Author, year } & \multicolumn{2}{|c|}{ Incisor region: Mean \pm SD } & \multicolumn{2}{|c|}{ Left molar region: Mean \pm SD } & \multicolumn{2}{|c|}{ Right molar region: Mean \pm SD } \\
\hline & Locking & Non-locking & Locking & Non-locking & Locking & Non-locking \\
\hline Agarwal et $\mathrm{al}^{4}$ & $16.76 \pm 9.34$ & $6.95 \pm 2.02$ & $63.07 \pm 21.30$ & $28.69 \pm 7.42$ & $58.43 \pm 20.25$ & $31.58 \pm 9.58$ \\
\hline Giri et al $^{14}$ & ND & ND & ND & ND & ND & ND \\
\hline Kumar et al ${ }^{15}$ & ND & ND & ND & ND & ND & ND \\
\hline Rastogi et al $^{16}$ & ND & ND & ND & ND & ND & ND \\
\hline
\end{tabular}

Abbreviations: ND, not declared; SD, standard deviation.

of follow-up. These results enable us to imply that the locking plate system promotes the reestablishment of masticatory functions earlier than the non-locking plate system. This may be due to the locking plate system's ability to join the fragments of the fracture without leaving gaps. ${ }^{12}$ In the nonlocking plates system, the existence of these gaps enables the formation of bony callus between the fragments of the fracture, delaying the repair process and thus reducing the effectiveness of this system. ${ }^{24}$

Four articles met the inclusion criteria for this study. $4,14-16$ Two of these articles presented identical results; ${ }^{14,16}$ therefore, the most recent article was excluded from the metaanalysis. ${ }^{16}$ Another study included in this review expressed the results in graphs, so it was not included in the metaanalysis due to the impossibility of extracting raw data such as mean and standard deviation. ${ }^{15}$ Despite the possibility of performing a meta-analysis with only two studies, ${ }^{25}$ this is a limitation of this study. The lack of studies is justified by the fact the other studies that investigated bite force comparing locking and non-locking plate systems were laboratory studies using finite element analysis, ${ }^{26}$ ex vivo human ${ }^{27}$ or animal ${ }^{28}$ parts, or a combination of methods, ${ }^{29}$ and they failed to meet the inclusion criteria adopted in this review.

In order to evaluate the bite force, one could use a dynamometer, ${ }^{30}$ a bite fork, ${ }^{31}$ or the indigenous Bite Force Recorder, which was used in all the studies included in this review. $^{4,14-16}$

In addition to the diversity of methods for measuring bite force, there is also no established standard anatomical sites used for this purpose. ${ }^{30,31}$ In this systematic review, all studies performed the measurement of bite force in the incisor, left molar and right molar regions, in agreement with the studies by Gupta and coleagues (2012) and Kshirsagar and colleagues (2011). ${ }^{32,33}$

To avoid possible biases and facilitate the comparison among future studies, a single measurement of bite force 
186 Bite Force with Locking Plates versus Non-Locking Plates in Mandibular Fractures Glória et al.

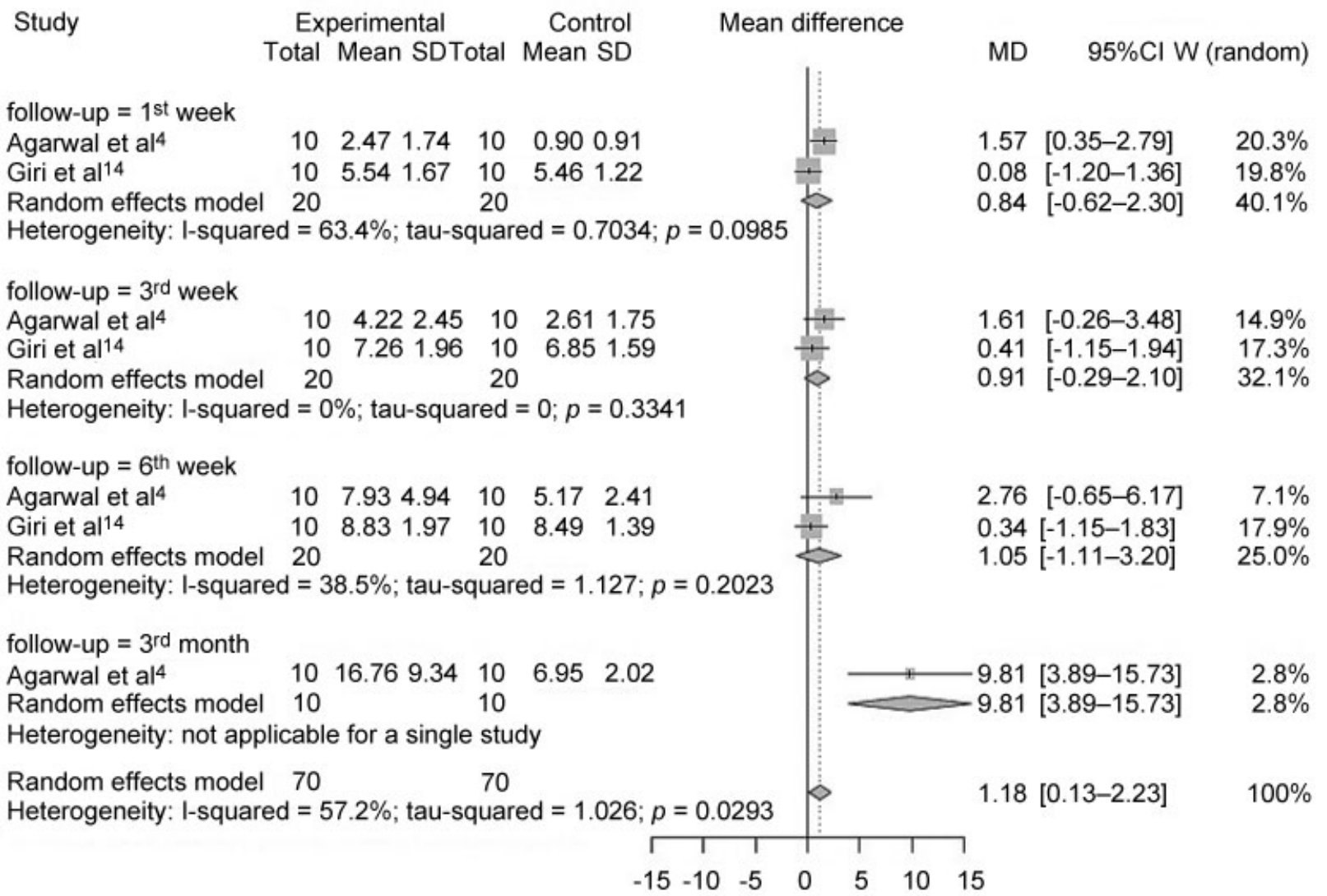

Fig. 3 Forest plot for the bite forces in the incisor region. Abbreviations: 95\%Cl, 95\% confidence interval; MD, mean deviation; SD, standard deviation.

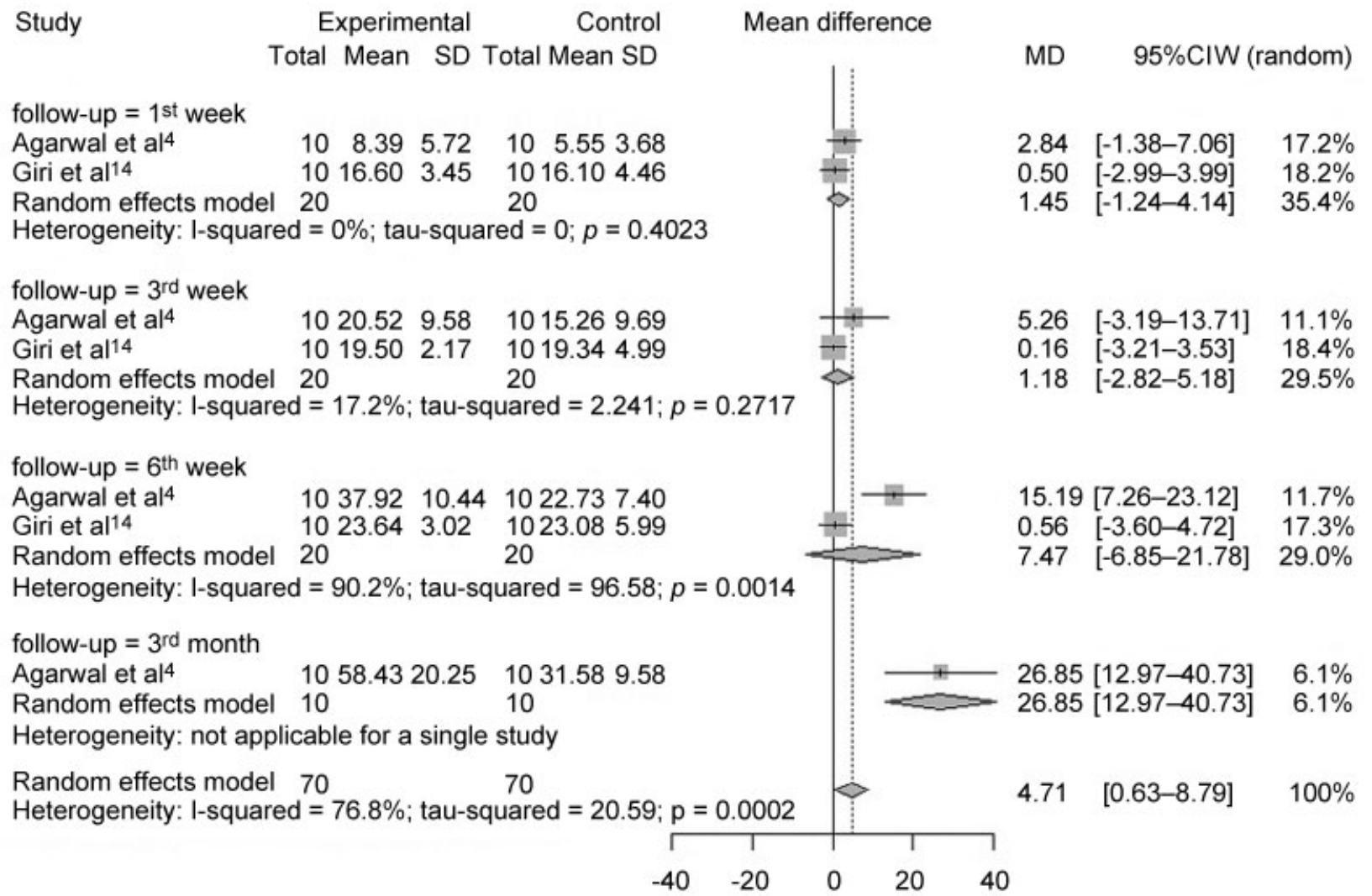

Fig. 4 Forest plot for the bite forces in the right molar region. Abbreviations: 95\%Cl, 95\% confidence interval; MD, mean deviation; SD, standard deviation. 


Experimental Control
Total Mean SD Total Mean SD

Total Mean SD Total Mean SD

follow-up $=1$ st week

Agarwal et $\mathrm{al}^{4}$

Giri et al 14

$1014.60 \quad 6.30 \quad 10 \quad 4.73 \quad 3.74$

Random effects model 20

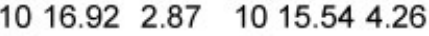

Heterogeneity: I-squared $=88.9 \%$; tau-squared $=32.04 ; p=0.0027$

follow-up $=3^{\text {rd }}$ week

Agarwal et $\mathrm{al}^{4}$

Giri et al14

1027.7911 .85

1019.832 .19

1012.235 .94

Random effects model 20 20

Heterogeneity: I-squared $=89.1 \%$; tau-squared $=84 ; p=0.0024$

follow-up $=6^{\text {th }}$ week

Agarwal et al 4

Giri et al14

1043.2713 .80 1022.692 .09

Random effects model 20

20

Heterogeneity: I-squared $=94.9 \% ;$ tau-squared $=246.5 ; p<0.0001$

follow-up $=3^{\text {rd }}$ month

Agarwal et $\mathrm{al}^{4}$

$1063.0721 .30 \quad 1028.697 .42$

Random effects model 10

10

Heterogeneity: not applicable for a single study

Random effects model 70

Heterogeneity: I-squared $=89.2 \%$; tau-squared $=49.19 ; p<0.0001$

Mean difference

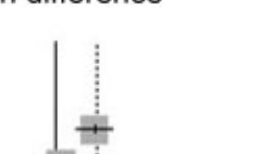

MD

$95 \% \mathrm{Cl}$ W (random) $\begin{array}{lll}9.87 & {[5.33-14.41]} & 16.0 \% \\ 1.38 & {[-1.80-4.56]} & 16.8 \% \\ 5.46 & {[-2.85-13.78]} & 32.8 \%\end{array}$

$15.56[7.34-23.78] \quad 13.1 \%$

$1.83[-1.54-5.20] \quad 16.7 \%$

$8.16[-5.25-21.58] \quad 29.8 \%$
24.28 [14.93-33.63] $12.1 \%$

$1.49[-2.27-5.25] \quad 26.5 \%$

$12.47[-9.85-34.79] \quad 28.6 \%$

$\begin{array}{lllll}-40 & -20 & 0 & 20 & 40\end{array}$

Fig. 5 Forest plot for the bite forces in the left molar region. Abbreviations: $95 \% \mathrm{Cl}, 95 \%$ confidence interval; $\mathrm{MD}$, mean deviation; $\mathrm{SD}$, standard deviation.

would enable a better evaluation of the performance of the plate systems, since there is no significant difference in the bite force between the fractured side and the non-fractured side ${ }^{30}$ because, in the immediate postoperative period, there is a reduction in this force caused by protective neuromuscular mechanisms. This single measurement could further help control the bias of measuring the bite forces of one edentulous side and another toothed side. In addition, it is suggested that the maximum bite force would be obtained after at least three attempts, since the first attempt at measuring should be considered a stage of adaptation to the technique by the patient. ${ }^{34}$ Some clinical parameters such as infection, malocclusion, hardware failure, wound dehiscence, paresthesia and pain may decrease the bite force of patients treated after mandibular fractures. ${ }^{13,19,30}$ Although it is difficult to establish what would be a short follow-up period following osteosynthesis surgeries, these factors may have contributed to the fact that in the followups of only a few weeks after surgery there were no significant differences in the means of the bite forces in the regions evaluated when comparing the fixation plates systems. This suggests that the success of the treatment is more related to bone quality, fracture site and surgical technique than to the type of plate system. ${ }^{13,19}$ This is a limitation that must be recognized in this review. Although the studies state that most of the treated fractures have occurred in the symphysis and mandibular parasymphysis regions, standardization cannot be achieved due to the peculiarities of each type of fracture. Other limiting factors that may influence the results of this review are the size of the plates and the size of the screws used in each type of fracture. ${ }^{35}$ Since there was some standardization during data collection for the bite force variable in the studies included in this meta-analysis, the high heterogeneity present in this review can be attributed to the variability of osteosynthesis techniques due to the peculiarity of each type of mandibular fracture treated.

The literature points to a higher financial cost of the locking system in relation to the non-locking system. ${ }^{36}$ However, it is possible that this cost difference is compensated by the increase in bite force in the third month of follow-up, and by the decrease in postoperative complications associated with the locking system. ${ }^{11,12}$ Cost-effectiveness studies are needed to compare the costs of each fracture fixation system with its respective impact on clinical outcomes, and to identify the best alternative for the treatment. The current review presents a summary of the effect of the measures regarding the bite force of patients treated with locking and non-locking plates, which may contribute to the validity of future economic analyzes.

\section{Final Comments}

There are some limitations to this study that cause these results to be evaluated with discretion. First, a limited number of articles were included in this review. Then, these articles presented unclear results on most bias risk criteria (according to the Cochrane Handbook for Systematic Reviews of Interventions) and an unadjusted presentation of the 
results. For a better consistency of the presented evidences, it is suggested that more clinical trials should be performed to evaluate the bite force, measuring the whole mouth in a single time, or even using electromyographic analysis to avoid possible biases. In addition, greater standardization of fracture site, and size of plates and screws used would increase the homogeneity of the results. Using the patient as his or her own control is also a way to standardize the analysis of the results in a more reliable way, which was not done by one of the four included studies. ${ }^{15}$ Once statistical significance was found only at the 3-month follow-up, a longer follow-up period should be considered in the next experiments, considering a reduced interval between the measurements in order to accurately estimate the moment of return to functional normality.

Although the results of this study indicated a better bite force result with the locking plates, there is still no sufficient evidence to support this information safely.

\section{References}

1 Almahdi HM, Higzi MA. Maxillofacial fractures among Sudanese children at Khartoum Dental Teaching Hospital. BMC Res Notes 2016:9:120

2 Ribeiro Ribeiro AL, da Silva Gillet LC, de Vasconcelos HG, de Castro Rodrigues L, de Jesus Viana Pinheiro J, de Melo Alves-Junior S. Facial Fractures: Large Epidemiologic Survey in Northern Brazil Reveals Some Unique Characteristics. J Oral Maxillofac Surg 2016; 74(12):2480.e1-2480.e12

3 Singaram M, G SV, Udhayakumar RK. Prevalence, pattern, etiology, and management of maxillofacial trauma in a developing country: a retrospective study. J Korean Assoc Oral Maxillofac Surg 2016;42(04):174-181

4 Agarwal M, Mohammad S, Singh RK, Singh V. Prospective randomized clinical trial comparing bite force in 2-mm locking plates versus $2-\mathrm{mm}$ standard plates in treatment of mandibular fractures. J Oral Maxillofac Surg 2011;69(07):1995-2000

5 Nabil Y. Evaluation of the effect of different mandibular fractures on the temporomandibular joint using magnetic resonance imaging: five years of follow-up. Int J Oral Maxillofac Surg 2016; 45(11):1495-1499

6 Conforte JJ, Alves CP, Sánchez MdelP, Ponzoni D. Impact of trauma and surgical treatment on the quality of life of patients with facial fractures. Int J Oral Maxillofac Surg 2016;45(05):575-581

7 Champy M, Loddé JP, Schmitt R, Jaeger JH, Muster D. Mandibular osteosynthesis by miniature screwed plates via a buccal approach. J Maxillofac Surg 1978;6(01):14-21

8 Champy M, Wilk A, Schnebelen JM. [Tretment of mandibular fractures by means of osteosynthesis without intermaxillary immobilization according to F.X. Michelet's technic]. Zahn Mund Kieferheilkd Zentralbl 1975;63(04):339-341

9 Haug RH, Street CC, Goltz M. Does plate adaptation affect stability? A biomechanical comparison of locking and nonlocking plates. J Oral Maxillofac Surg 2002;60(11):1319-1326

10 Alpert B, Gutwald R, Schmelzeisen R. New innovations in craniomaxillofacial fixation: the 2.0 lock system. Keio J Med 2003;52 (02):120-127

11 Collins CP, Pirinjian-Leonard G, Tolas A, Alcalde R. A prospective randomized clinical trial comparing 2.0-mm locking plates to 2.0-mm standard plates in treatment of mandible fractures. J Oral Maxillofac Surg 2004;62(11):1392-1395

12 Gutwald R, Alpert B, Schmelzeisen R. Principle and stability of locking plates. Keio J Med 2003;52(01):21-24
13 Chrcanovic BR. Locking versus non-locking plate fixation in the management of mandibular fractures: a meta-analysis. Int J Oral Maxillofac Surg 2014;43(10):1243-1250

14 Giri KY, Sahu P, Rastogi S, et al. Bite Force Evaluation of Conventional Plating System Versus Locking Plating System for Mandibular Fracture. J Maxillofac Oral Surg 2015;14(04):972-978

15 Kumar S, Gattumeedhi SR, Sankhla B, Garg A, Ingle E, Dagli N. Comparative evaluation of bite forces in patients after treatment of mandibular fractures with miniplate osteosynthesis and internal locking miniplate osteosynthesis. J Int Soc Prev Community Dent 2014;4(Suppl 1):S26-S31

16 Rastogi S, Reddy MP, Swarup AG, Swarup D, Choudhury R. Assessment of Bite Force in Patients Treated with 2.0-mm Traditional Miniplates versus 2.0-mm Locking Plates for Mandibular Fracture. Craniomaxillofac Trauma Reconstr 2016;9(01):62-68

17 Borenstein M, Hedges LV, Higgins J, Rothstein HR. Random-Effects Model. Introduction to Meta-analysis 2009:69-75

18 Higgins JP, Thompson SG. Quantifying heterogeneity in a metaanalysis. Stat Med 2002;21(11):1539-1558

19 Zhan S, Jiang Y, Cheng Z, Ye J. A meta-analysis comparing the 2.0-mm locking plate system with the $2.0-\mathrm{mm}$ nonlocking plate system in treatment of mandible fractures. J Craniofac Surg 2014; 25(06):2094-2097

20 Hatch JP, Shinkai RS, Sakai S, Rugh JD, Paunovich ED. Determinants of masticatory performance in dentate adults. Arch Oral Biol 2001;46(07):641-648

21 Koc D, Dogan A, Bek B. Bite force and influential factors on bite force measurements: a literature review. Eur J Dent 2010;4(02): 223-232

22 Okiyama S, Ikebe K, Nokubi T. Association between masticatory performance and maximal occlusal force in young men. J Oral Rehabil 2003;30(03):278-282

23 Said MM, Otomaru T, Aimaijiang Y, Li N, Taniguchi H. Association Between Masticatory Function and Oral Health-Related Quality of Life in Partial Maxillectomy Patients. Int J Prosthodont 2016; 29(06):561-564

24 Henderson CE, Lujan T, Bottlang M, Fitzpatrick DC, Madey SM, Marsh JL. Stabilization of distal femur fractures with intramedullary nails and locking plates: differences in callus formation. Iowa Orthop J 2010;30:61-68

25 Shrier I. Cochrane Reviews: new blocks on the kids. Br J Sports Med 2003;37(06):473-474

26 Bujtár P, Simonovics J, Váradi K, Sándor GK, Avery CM. The biomechanical aspects of reconstruction for segmental defects of the mandible: a finite element study to assess the optimisation of plate and screw factors. J Craniomaxillofac Surg 2014;42(06): 855-862

27 Grohmann I, Raith S, Kesting M, et al. Experimental biomechanical study of the primary stability of different osteosynthesis systems for mandibular reconstruction with an iliac crest graft. $\mathrm{Br} \mathrm{J}$ Oral Maxillofac Surg 2013;51(08):942-947

28 Miller EI, Acquaviva AE, Eisenmann DJ, Stone RT, Kraus KH Perpendicular pull-out force of locking versus non-locking plates in thin cortical bone using a canine mandibular ramus model. Vet Surg 2011;40(07):870-874

29 Goulart DR, Kemmoku DT, Noritomi PY, de Moraes M. Development of a Titanium Plate for Mandibular Angle Fractures with a Bone Defect in the Lower Border: Finite Element Analysis and Mechanical Test. J Oral Maxillofac Res 2015;6(03):e5

30 Pepato AO, Palinkas M, Regalo SC, et al. Effect of surgical treatment of mandibular fracture: electromyographic analysis, bite force, and mandibular mobility. J Craniofac Surg 2014;25(05): 1714-1720

31 Gerlach KL, Schwarz A. Bite forces in patients after treatment of mandibular angle fractures with miniplate osteosynthesis according to Champy. Int J Oral Maxillofac Surg 2002;31(04): $345-348$ 
32 Gupta A, Singh V, Mohammad S. Bite force evaluation of mandibular fractures treated with microplates and miniplates. J Oral Maxillofac Surg 2012;70(08):1903-1908

33 Kshirsagar R, Jaggi N, Halli R. Bite force measurement in mandibular parasymphyseal fractures: a preliminary clinical study. Craniomaxillofac Trauma Reconstr 2011;4(04):241-244

34 Araújo SCCSd, Vieira MM, Gasparotto CA, Bommarito S. Bite Force Analysis in Different Types of Angle Malocclusions. Rev CEFAC 2014;16(05):1567-1578
35 de Medeiros RC, Sigua EA, Navarro P, Olate S, Albergaria Barbosa JR. In Vitro Mechanical Analysis of Different Techniques of Internal Fixation of Combined Mandibular Angle and Body Fractures. J Oral Maxillofac Surg 2016;74(04):778-785

36 Poon CC, Verco S. Evaluation of fracture healing and subimplant bone response following fixation with a locking miniplate and screw system for mandibular angle fractures in a sheep model. Int J Oral Maxillofac Surg 2013;42(06): 736-745 